INDIAN JOURNAL OF POWER \& RIVER VALLEY DEVELOPMENT www.ijprvd.info

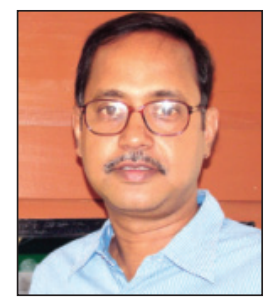

\title{
Coal-fired power plants, health impacts and some planning inputs
}

Particulate pollutants of sizes below 2.5 micron, also known as PM2.5 is a significant environmental risk factor for human health. PM2.5 intake in the catchment area results in, among other things, premature mortality cases and put heavy burdens on the socio-economic fabrics in the areas, even far beyond the areas visibly affected. The global implications are enormous. For example, in China has some of the highest concentrations of PM2.5 in the world, many others can take the comfort of not knowing it, contributed by the power plants. In 2010, the population-weighted average concentration of PM2.5 in China was $59 \mu \mathrm{g} \mathrm{m}^{-3}$, which was 1.69 times the national standard (i.e., $35 \mu \mathrm{g} \mathrm{m}^{-3}$ ). According to the Global Burden of Disease Study (GBD), PM2.5 (i.e., fine particulate matter with an aerodynamic diameter smaller than $2.5 \mu \mathrm{m}$ ) has been identified as a leading environmental risk factor contributing to the global human disease burden. PM2.5 exposure triggers five notable adverse health impacts in humans: ischemic heart disease (IHD), cerebrovascular disease (stroke), chronic obstructive pulmonary disease (COPD), lung cancer (LC), and lower respiratory infections among the young. It contributes to a lot of premature mortality cases (PMC), i.e., death much before the average age of death of a population. Needless to say, the poor people pay a heavy price for such pollution.

Coal-fired power plants are the major power sources and air pollution sources. During 2010, $\mathrm{PM} 2.5, \mathrm{SO}_{2}$ and $\mathrm{NO}_{\mathrm{x}}$ emitted from coal-fired power plants accounted for $7.3 \%$, $28.4 \%$ and $32.4 \%$ of the corresponding total emissions in China, according to Global Power Emissions Database, 2018. Considering acceptance of China's severe air pollution problem and the significant contribution of coal-fired power plants on it, the similarities and even aggravated effects can be drawn in the countries like India, Indonesia, Vietnam and many other poorer countries. There is a growing need to assess the health impacts and the corresponding economic losses induced by PM2.5 from coal-fired power plants in all these countries for guiding the relevant policy development to ensure long-term equitable and social welfare.

\begin{tabular}{|c|c|c|c|c|}
\hline \multicolumn{5}{|c|}{$\begin{array}{l}\text { Estimated health impacts by state due to } \\
\mathrm{PM}_{2 .} \text { pollution from the coal-fired TPPs in India }\end{array}$} \\
\hline & 2017 & 2020 & 2025 & 2030 \\
\hline Andhra Pradesh & 9.870 & 12,170 & 15,170 & 17,510 \\
\hline Arunachal Pradesh & 70 & 90 & 110 & 130 \\
\hline Assam & 1,780 & 2,160 & 2,800 & 3,300 \\
\hline Bihar & 9,450 & 11.070 & 14,410 & 16,410 \\
\hline Chhattisgarh & 3,870 & 4.610 & 5.600 & 6,340 \\
\hline Delhi & 1.520 & 1.640 & 1.880 & 2.090 \\
\hline Goa & 120 & 140 & 180 & 200 \\
\hline Gujarat & 4,300 & 4880 & 5,890 & 6.690 \\
\hline Haryana & 2,080 & 2,260 & 2.630 & 2,940 \\
\hline Himachal Pradesh & 280 & 300 & 370 & 410 \\
\hline Jammu \& Kashmir & 360 & 400 & 480 & 530 \\
\hline Jharkhand & 4.120 & 4,940 & 6,340 & 7.190 \\
\hline Karnataka & 5.170 & 6,340 & 7,940 & 9,160 \\
\hline Kerala & 1.660 & 2.000 & 2.530 & 2,980 \\
\hline Madhya Pradesh & 6.790 & 7,970 & 9.700 & 10,940 \\
\hline Maharashtra & 11.580 & 13860 & 16,870 & 19.010 \\
\hline Manipur & 180 & 220 & 280 & 330 \\
\hline Meghalaya & 190 & 230 & 300 & 350 \\
\hline Mizoram & 70 & 90 & 110 & 130 \\
\hline Nagaland & 130 & 160 & 200 & 230 \\
\hline Odisha & 6,100 & 7,560 & 9,380 & 10,740 \\
\hline Punjab & 1,470 & 1,600 & 1,920 & 2,140 \\
\hline Rajasthan & 4,340 & 4860 & 5,800 & 6,510 \\
\hline Sitkim & 30 & 30 & 40 & 50 \\
\hline Tamilnadu & 5.080 & 6,110 & 7.650 & 9,020 \\
\hline Tripura & 200 & 240 & 320 & 370 \\
\hline Uttar Pradesh & 16,470 & 18,740 & 22,870 & 26,000 \\
\hline Uttarakhand & 390 & 440 & 540 & 610 \\
\hline West Bengal & 12,360 & 14,470 & 18,060 & 20,440 \\
\hline
\end{tabular}

Figure represents the total premature mortality scenario due to the emissions from coal-fired thermal power plants in India that are expected to grow 2-3 times reaching $1,86,500$ to $2,29,500$ annually in 2030. Asthma cases associated with coal-fired thermal power plant emissions will grow to 42.7 million by 2030(Source: https:// indiaairquality.info/emissions-power-plants/).

Now some of the policy steps that can be taken, need discussion:

1. Atmospheric dispersion models can point to the plants that have most prominent effects on the macro-climate and thus affect larger population compared to others. Such models can determine where the plants of certain size should be sited and preferably, where not.

2. Size matters. Large plants have better capacity to control pollution. They can better respond to the technological modifications. So instead of having small size plants distributed over an area, a large plant can be suitably located.

3. Considering the enormously fixed electricity demand of the metropolis, efficient power plants and smart grids are rational in the short term. However, for the long term, constructing the required infrastructure for natural gas or biomass or even, solar or wind hybrid thermal power plant are now. 